\title{
Etanol: 40 anos de evolução do mercado de combustíveis e automóveis no Brasil
}

\author{
Vinicius Pacheco de Almeida* \\ Giuliano Manera Longhi** \\ Lucas Ramos dos Santos****
}

\begin{abstract}
Resumo
Este artigo tem o objetivo de analisar, historicamente, com os dados pertinentes, como se comportou o mercado de combustíveis e de automóveis a partir do projeto governamental, Proálcool, até 2014, no qual foram utilizados dados da moagem da cana-de-açúcar separados pelo seu destino final, açúcar ou etanol, observando, também, o mercado automobilístico separado pelo tipo de combustível aceito por cada motor.
\end{abstract}

Palavras-chave: Etanol. Mercado automobilístico. Mercado de combustível. Proálcool.

* Mestrando no Programa de Pós-Graduação em Economia e Desenvolvimento da Universidade Federal de Santa Maria (UFSM). E-mail: viniciuspacheco33@yahoo.com.br

* Mestrando no Programa de Pós-Graduação em Economia e Desenvolvimento da UFSM. E-mail: Giuliano.longhi@hotmail.com

*** Mestrando no Programa de Pós-Graduação em Economia e Desenvolvimento da UFSM. E-mail: lucasramoseconomia@gmail.com

http://dx.doi.org/10.5335/rtee.v23i49.8260

Submissão: 21/06/2016. Aceite: 24/04/2017. 


\section{Introdução}

O Brasil se destaca perante outros países por ter $45 \%$ de sua matriz energética, em todos os usos energéticos, a partir de fontes de energia renováveis (LOBÃO, 2008a), principalmente no desenvolvimento de bioenergia à base de cana-de-açúcar. Essa matriz energética que vem do campo tem uma longa história de aclives e declives na economia nacional, a partir dos anos 1970 até ser utilizada pelos carros com etanol que já saem das fábricas com motor flex-fuel, no qual o carro pode utilizar como combustível tanto álcool quanto gasolina, sendo que a gasolina utilizada no Brasil já tem em sua composição uma porcentagem de etanol.

Nos Estados Unidos, o etanol envolve o debate do desabastecimento alimentar, pois o álcool americano é feito a partir do insumo milho. Já o álcool brasileiro é produzido a partir da cana-de-açúcar, com sucesso há pelo menos 40 anos na produção de combustível para fins veiculares, lembrando que o plantio da cana-de-açúcar é base da agricultura brasileira desde o início da colonização portuguesa.

O sucesso do etanol no Brasil é fruto de anos de investimentos do governo, começando fortemente em 1975 com o lançamento do projeto governamental Proálcool, em meio à crise do petróleo mundial, com a criação do cartel que diminuiu a oferta de petróleo no mundo, elevando os preços dessa commodity tão essencial para a economia mundial. O Brasil importava $80 \%$ do óleo bruto consumido no país (LOBÃO, 2008b), e foi atingido fortemente pela primeira crise do petróleo, fazendo com que houvesse um grande déficit em conta corrente.

O objetivo principal do projeto era diminuir as importações brasileiras de petróleo após a crise energética mundial, que quadruplicou os preços do petróleo. De 1975 a 1979, o programa começou aumentando a mistura de etanol na gasolina. Em sua segunda fase, de 1979 a 1985, o programa evoluiu e passou a promover o uso do etanol como combustível principal, com carros movidos exclusivamente a álcool, aumentando substancialmente sua participação na matriz energética nacional.

A partir de meados da década de 1980, o programa começou a ter problemas, devido ao contrachoque do petróleo, que baixou os preços do barril de petróleo, e o etanol deixou de ser competitivo com a gasolina. No mercado internacional, elevou-se o preço do açúcar, fazendo com que os usineiros preferissem produzir açúcar a álcool. O país passava por uma grande onda de inflação, o que fez com que o governo federal diminuísse os subsídios para os produtores de cana-de-açúcar. Esse conjunto de fatores fez com que o projeto entrasse em crise e se mantivesse praticamente estagnado na década de 1990. 
O etanol saiu das cinzas em 2003, com as melhorias tecnológicas que avançaram nos motores a combustão interna de ciclo Otto e uma nova realidade onde combustíveis renováveis teriam possibilidade de figurar como alternativa viável no mercado. Com a criação do sistema flex-fuel, os carros podem funcionar conjuntamente com gasolina e etanol, dando ao consumidor a oportunidade de avaliar qual combustível é mais vantajoso quanto ao preço e ao desempenho.

Nasce, então, uma nova situação econômica para o mercado de combustíveis, pois o álcool e o combustível fóssil viraram substitutos perfeitos do ponto de vista do consumidor, mas não no aspecto monetário, porque energeticamente o biocombustível tem uma conversão energética inferior se comparado a do fóssil. Além disso, existiu um movimento de alta do barril do petróleo e voltou a ter competitividade o combustível renovável, de tal forma que ultrapassou as fronteiras brasileiras.

Este trabalho é desenvolvido em dois tópicos. A primeira parte tem o objetivo de analisar, do ponto de vista histórico, a cana-de-açúcar como produção agrícola e como alternativa de combustível, com destaque a partir do Proálcool até a entrada da tecnologia automobilística dos motores flexíveis. Já a segunda apresenta uma análise do mercado dos produtos à base de cana-de-açúcar. Logo, o trade-off entre açúcar e etanol, e como produtos de mesma matéria-prima e não complementares, interfere no preço e no mercado de ambos os produtos. O objetivo secundário é discorrer sobre como o álcool colocou o Brasil na vanguarda da utilização de energia renovável, proveniente do etanol. Ao enfrentar as crises mundiais vividas a partir da década de 1970, o país encontrou um meio de manter "limpa" sua matriz energética e de tentar resolver seus problemas econômicos em sua balança comercial.

\section{Cana-de-açúcar e o caso Brasil}

\subsection{Uma breve história da cana-de-açúcar no Brasil}

Na história brasileira, desde os tempos do Brasil colônia, a cana-de-açúcar sempre teve um papel importante na economia, a base exportadora foi o açúcar até meados de 1700 , tendo sido o seu cultivo a primeira atividade economicamente organizada (FURTADO, 1975). Ao longo do tempo, o açúcar deixou de ser o principal produto de exportação, pois os holandeses começaram a produzir açúcar na América Central, o que pressionou a queda dos preços, mas continuou sendo um dos cultivos de grande importância para a exportação. Celso Furtado ressalta a importância e a força da cana-de-açúcar para a economia brasileira:

Teoria e Evidência Econômica - Ano 23, n. 49, p. 462-484, jul./dez. 2017 
[...] a economia açucareira do Nordeste brasileiro, com efeito, resistiu mais de três séculos às mais prolongadas depressões, logrando recuperar-se sempre que o permitiam as condições do mercado externo, sem sofrer nenhuma modificação estrutural significativa (FURTADO, 1975, p. 61).

Nos engenhos de açúcar do Brasil colônia, a produção do açúcar, a partir do caldo da cana-de-açúcar, tinha um subproduto, a princípio, sem valor comercial: o álcool etanol (SANTOS, 1982). Apesar das navegações pelo Atlântico já serem uma realidade comercial na época, a importação de qualquer produto da Europa sempre tinha elevado valor, para substituir a importação das bebidas vindas pelos navios, o subproduto da cana, a cachaça, serviu como uma substituição de importação de baixo custo de produção que logo ganhou o país (SANTOS, 1982).

Do passado do engenho para a usina atual, a produção tanto de açúcar quanto de álcool tem um modelo distinto de configuração básica. Dessa forma, com a variação no mercado dos preços do açúcar e do álcool, o produtor tem a capacidade de avaliar qual produto final lhe dará o maior potencial econômico e, assim, variar a quantidade de um ou outro produto. Isso faz com que o produtor leve vantagens frente a outros cultivos agrícolas, perante as intempéries da safra e dos preços de mercado (SANTOS, 1982).

O produtor ainda tem mais vantagem com o avanço da tecnologia nos últimos anos. Nas usinas sucroalcooleiras, estão conseguido criar mais um fim para esse tão variado insumo. A partir da utilização dos rejeitos de produção, que são palha e bagaço, as usinas estão se capacitando, com fim de gerar eletricidade a partir de biocombustores. Essa matéria-prima, já utilizada há 40 anos, não para de surpreender o mundo, desde o projeto governamental do Proálcool até os dias atuais, o esforço brasileiro pode ser considerado um dos maiores projetos já vistos para a substituição do combustível fóssil para a energia renovável.

\subsection{Década de 1970}

O acordo de Bretton Woods foi firmado pelos países no pós-segunda guerra e tinha como pilares o regime de câmbio fixo e a paridade dólar ouro, mas os Estados Unidos quebrou o acordo em 1970, acarretando uma desestabilização do mercado internacional, logo, houve movimentos especulativos de capitais internacionais e instabilidade cambial, afetando diretamente o mercado de commodities e elevando o preço do petróleo. Nesse cenário da crise do petróleo e do fim do acordo de Bretton Woods, nasceu a história do Proálcool, em 1973 (BELLUZZO, 1995). 
Segundo Carneiro (2002), em sua obra Desenvolvimento em crise, após o fim do tratado de Bretton Woods, a economia mundial ficou muito fragilizada.

Desaceleração do crescimento do Produto Interno Bruto - PIB dos países industrializados e do comércio internacional, perda das relações de troca, diminuição das formas de financiamento de maior estabilidade em benefício de outras mais caras e instáveis: tais foram os percalços para a periferia do mundo capitalista, oriundos da desagregação da ordem internacional Bretton Woods (2002, p. 55 ).

A crise foi agravada a partir da criação da Organização dos Países Exportadores de Petróleo (Opep), o que elevou o preço da gasolina como nunca visto no mundo moderno. $\mathrm{O}$ impacto foi grande no mundo inteiro, mas os países que estavam começando a se desenvolver tinham forte dependência da matriz energética fóssil não renovável, pelo enquadramento do padrão de desenvolvimento brasileiro no paradigma metal-mecânico-químico e a subsequente escolha pela expansão das rodovias para escoamento da produção interna (PIMENTEL, 2006).

Como o movimento de elevação dos preços do petróleo e seus derivados, a principal matriz energética da economia mundial, implicou no aumento dos custos marginais de produção, isso viabilizou a utilização de alternativas tecnológicas para produção de energia, uma vez que o preço da energia subiu, assim, foi possível investir em novas tecnologias para fontes de energia alternativa, com custos marginais de produção mais altos aparecendo no cenário (PIMENTEL, 2011).

O Brasil foi pioneiro ao lançar um projeto maciço de biocombustível em 1975, por causa da imensa dependência de importação de petróleo, causando desequilíbrio em sua balança comercial e grandes dívidas nos cofres públicos. O Brasil tinha vantagem frente aos outros países, pois já tinha experiência na utilização do álcool, mas nunca tinha sido realizada uma campanha nacional, desde os anos 1930. Em 1933, foi criado o Instituto do Açúcar e do Álcool (IAA), como o principal órgão planejador do setor, regulamentando o álcool e o açúcar no Brasil. Em 1938, o IAA tornou obrigatória a mistura do álcool anidro na gasolina. No ano de 1942, foi decretado preço mínimo para o álcool, a fim de valorizar a indústria alcooleira, tendo como limite $22 \%$ de álcool na mistura, e com o insumo da cana-de-açúcar com um baixo nível de preço, esta foi a solução ideal para o Brasil enfrentar a crise (MARJOTTA-MAISTRO, 2002).

O açúcar, desde o Brasil colônia, foi uma das principais pautas de importação do país, mas viveu uma crise na década de 1970, com o baixo nível de preço no mercado internacional, o governo não conseguia as divisas para acompanhar a elevação do preço do barril de petróleo. O Proálcool apareceu para solucionar os dois grandes problemas da balança de pagamento nacional (NITSCH, 1991). 
Com o projeto, o governo tinha a intenção de controlar a balança de pagamentos com a adição do álcool na gasolina, diminuindo a demanda de petróleo, o que, logo, levaria a uma queda na importação do combustível fóssil e, por conseguinte, diminuiria a produção de açúcar; com uma menor oferta de açúcar no mercado internacional, o preço teria a tendência de se elevar (NITSCH, 1991).

Tal movimento era necessário para garantir o modelo que o Brasil seguia, tendo como base da sua industrialização a indústria automobilística e como gargalo as estradas com um nível crescente de carros e caminhões, esse aumento dos preços dos combustíveis estava indo na contramão do modelo de desenvolvimento do país (NITSCH, 1991).

Segundo Baccarin (2005), o decreto do Proálcool, em 14 de novembro de 1975, constituiu a Comissão Nacional do Álcool (CNAI) e determinou as condições de financiamento para que o complexo sucroalcooleiro expandisse a produção de álcool. Os objetivos declarados do Proálcool eram os seguintes:

1 economizar divisas, por meio da substituição de importação de combustível e matérias-primas derivados do petróleo;

2 reduzir as disparidades regionais de renda, visto que praticamente todas as áreas do país, inclusive as de baixa renda, dispunham das condições mínimas necessárias para a produção de matérias-primas para o álcool em volume adequado, sobretudo em se tratando da mandioca;

3 reduzir as disparidades individuais de renda, por meio do apoio ao setor agrícola e, dentro deste, a produtos altamente intensivos quanto ao uso de mão de obra;

4 aumentar a renda interna, pelo emprego de fatores de produção ora ociosos, ou em desemprego disfarçado (terra e mão de obra, principalmente), considerando que se pode orientar a localização das culturas para onde haja disponibilidade;

5 expandir a produção de bens de capital, por meio da crescente colocação de encomendas de equipamentos com alto índice de nacionalização, destinados a ampliação, modernização e implantação de destilarias.

A Tabela 1 mostra o crescimento no investimento nos projetos para aperfeiçoamento do álcool no setor automotivo. Esse investimento foi governamental e privado, por parte das grandes montadoras. 
Tabela 1 - Proálcool: número de projetos enquadrados, montante de investimentos, capacidade de produção e produção real de álcool (1975-1979)

\begin{tabular}{c|c|c|c|c|c}
\hline \multirow{2}{*}{ Anos } & \multicolumn{2}{|c|}{$\mathrm{N}^{\circ}$ de projetos } & \multirow{2}{*}{$\begin{array}{c}\text { Investimentos } \\
\text { (US\$ milhões) }\end{array}$} & $\begin{array}{c}\text { Capacidade de } \\
\text { Produção } \\
\text { (milhões/litros) }\end{array}$ & $\begin{array}{c}\text { Produção de álcool } \\
\text { (milhões/litros) }\end{array}$ \\
\cline { 2 - 3 } 1975 & 2 & 2 & - & 54,5 & 555,6 \\
1976 & 69 & 71 & 113,7 & $1.681,5$ & 642,2 \\
1977 & 38 & 10 & 378,1 & $2.813,1$ & $1.387,7$ \\
1978 & 60 & 9169 & 282,7 & $4.330,6$ & $2.359,1$ \\
1979 & 39 & 208 & 245,4 & $5.285,5$ & $3.448,3$ \\
$1975 / 1979$ & 42 & - & 204,0 & $2.833,0$ & $1.678,6$ \\
\hline
\end{tabular}

Fonte: CENAL (1988, 1990 apud CAVALCANTI, 1992).

Em 1975, sem os investimentos necessários, a produção real de álcool era de 555,6 milhões de litros. Já em 1976, com a existência dos incentivos governamentais e investimentos diretos, cerca de 113,7 milhões de dólares foram utilizados; no mesmo ano, a produção de álcool subiu para 642,2 milhões. No final da década, em 1979, os investimentos foram de 245,4 milhões de dólares e com uma produção de 3.448,3 litros, portanto, em quatro anos, a produção teve um crescimento seis vezes maior do que em 1975.

\subsection{Década de 1980}

No início da década de 1980, existiram alguns fatores que deram força para impulsionar o programa do Proálcool, o novo aumento dos níveis de preço do petróleo, por causa da guerra entre o Iraque e o Irã, em 1980, fez com que, no primeiro momento da guerra, houvesse uma queda repentina de $10 \%$ da oferta de petróleo mundial (FRAQUELLI, 2014). Junto a esse fato, houve a criação de um motor de combustão interna para carros que funcionavam totalmente movidos a álcool, tendo como componente de seu combustível o etanol hidratado.

O governo designou a Petrobras para administrar o sistema global do novo combustível, tendo também como colaboradores as montadoras multinacionais que desenvolveriam os carros a álcool. Em contrapartida, o país iria fornecer o combustível a um preço competitivo perante a gasolina, para incentivar o consumo do combustível renovável e as vendas dos carros movidos somente a álcool (NITSCH, 1991). 
No dia 12 de maio de 1981, o Banco Mundial emprestou 250 milhões de dólares $^{1}$ para o Brasil investir em pesquisa e tecnologia, aprimorando assim o biocombustível. Tal investimento foi feito mesmo que o etanol não fosse viável economicamente, isso foi possível, porque, com o crescimento do preço do petróleo a níveis cada vez mais altos, aumentava a urgência mundial para encontrar um combustível que não precisasse do petróleo como matriz.

As nações desenvolvidas realizam movimentos de altas generalizadas de suas taxas de juros, medida que favorece fugas dos investidores que vinham apostando em retornos elevados de aplicações no Brasil. O país vê sua dívida crescer insustentavelmente. Os preços do petróleo permanecem elevados até 1986, quando se reestabilizam e colocam em cheque a eficiência do Proálcool (IPEA, 2010).

Com os preços do petróleo mais comportados, o combustível vegetal se torna um negócio desfavorável, tanto para o motorista quanto para o produtor. Além disso, os usineiros brasileiros se aproveitam do aumento da cotação do açúcar no mercado internacional e deixam de lado a produção do álcool, menos rentável. Nas bombas, motoristas começam a ter dor de cabeça para encher o tanque. O golpe de misericórdia no Proálcool vem no fim da década de 1980, quando as montadoras desistem de produzir carros novos movidos a etanol (IPEA, 2010).

O Brasil enfrentava uma grave crise financeira, com elevadas taxas de inflação. Dessa forma, o álcool ganhou força perante a população, por ser um combustível mais barato e nacional, diferente da gasolina, que era importada, apesar de todos os outros fatores que derrubavam a existência do Proálcool (NITSCH, 1991).

Mesmo o país tendo o know-how para a extração do petróleo bruto do fundo do mar, a ponto de exportar, via-se obrigado a comprar a gasolina e outros derivados do petróleo a preços mais altos do que vendia o petróleo nacional. Esse movimento econômico de vender mais barato do que comprar levava ao déficit da balança comercial, piorando ainda mais a situação econômica do país, que era cada vez mais grave.

\subsection{Década de 1990}

Os anos de 1990 são conhecidos como a década perdida para o álcool, quando entrou em discussão a sobrevivência do Proálcool. Segundo De Souza e Macedo (2010, p. 144), as causas foram os preços do petróleo, que se estabilizou a um nível aceitável, e do açúcar, que se elevou, fazendo com que, por consequência, os produtores diminuíssem a oferta de cana-de-açúcar para a produção do álcool. Com a abertura do mercado nacional para veículos importados (sobretudo a gasolina), a demanda 
por automóveis movidos a etanol despencou, de modo que, a partir de 1995, manteve-se abaixo de 5\%, resultando na desaceleração do valor do etanol e no desestímulo do Proálcool (DE SOUZA; MACEDO, 2010).

O preço do açúcar começou a subir a partir de 1985 e continuou a crescer até 1990, o que diminuiu o atrativo dos produtores pelo álcool, declinando, assim, sua produção, como se observa no Gráfico 1. Pela lei da demanda e oferta, os usineiros preferiram produzir mais açúcar do que álcool. Com a queda na oferta do combustível, o álcool ficou escasso no mercado, e o aumento de preço foi considerável nas bombas dos postos de combustível. As crises sucessivas de abastecimento aliadas ao maior consumo do álcool pelos automóveis movidos a esse tipo de combustível, devido às campanhas feitas para incentivo do consumo de carros movidos a álcool, levaram à descrença do consumidor. Por quase toda a década de 1990, carros a álcool se tornaram irrelevantes. O Proálcool estava à beira do fracasso.

Gráfico 1 - Evolução dos preços (em centavos de dólar por quilograma US\$ /kg) do açúcar entre 1980 e 2006

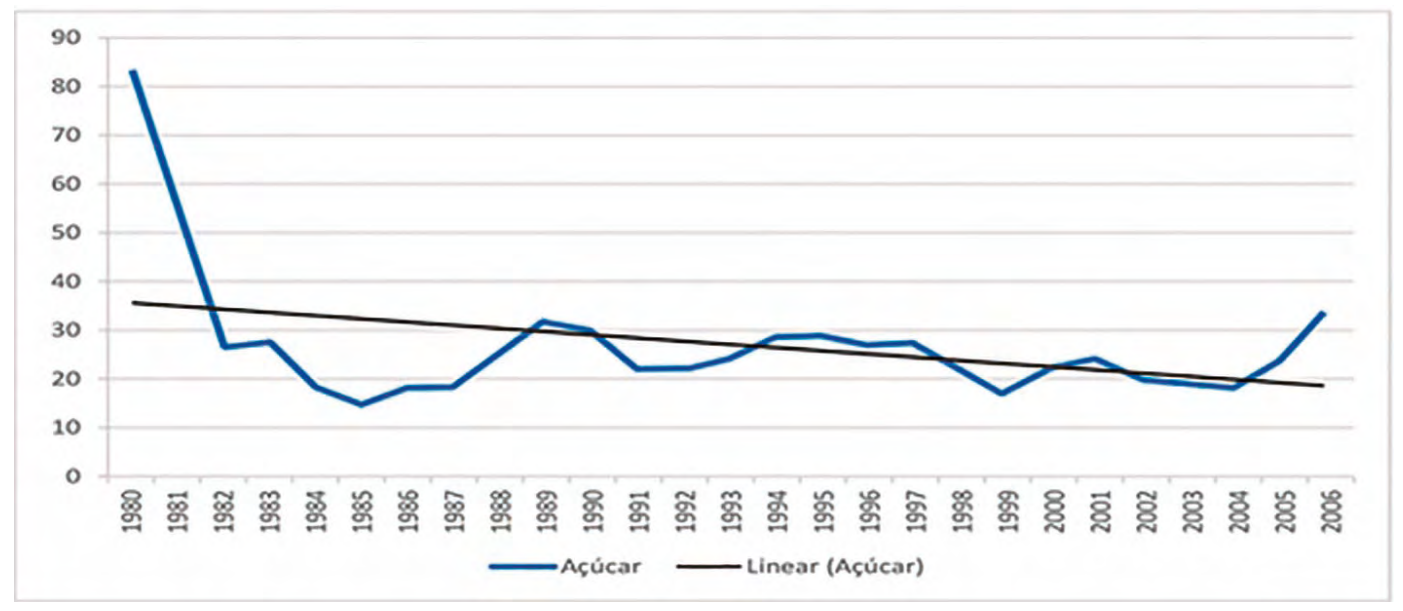

Fonte: Mathias (2014).

Analisando o Gráfico 1, percebe-se que, no início dos anos 1980, o preço em dólar do açúcar entrou em queda, mas começou a se elevar em 1985, continuando até o início de 1990, o que foi prejudicial para o Proálcool, pois, durante toda a década de 1990 e o início do novo milênio, o preço do açúcar se manteve num patamar acima da mínima de 1985, começando a se elevar apenas em 2005 e 2006.

A variação do preço do petróleo e a evolução do preço do açúcar demonstram como o etanol entrou na década de 1980 com expectativas positivas para 
investimentos, com queda no preço do açúcar e alta no do petróleo, mas, ao longo das décadas de 1980 e 1990, essa tendência se reverteu, com a alta no preço do açúcar e a queda no do petróleo, de tal forma que a continuação do projeto foi questionada.

\subsection{Etanol anidro e hidratado}

Existem duas formas de etanol, o hidratado e o anidro. A diferença é que o hidratado é o etanol comum, com o qual os consumidores abastecem os automóveis a álcool ou flex-fuel, enquanto o etanol anidro é aquele que é misturado com a gasolina vendida no país. A diferença técnica entre os dois está relacionada à quantidade de água presente em cada um. O etanol hidratado possui em sua composição teor mínimo de $92,6 \%$ e teor máximo de 93,8\% de etanol, com o restante de água; já o etanol anidro, teor mínimo de 99,3\% e teor máximo de 99,6\% de etanol. ${ }^{2}$ Dessa forma, o álcool anidro é praticamente sem água, logo, um etanol mais puro.

Os processos de fabricação dos dois tipos de álcool são praticamente iguais, a diferença começa na fermentação, quando surge o álcool hidratado, com uma taxa de aproximadamente $95 \%$ de etanol. Para produzir o álcool anidro, é preciso passar o etanol pelo processo de desidratação, que ocorre com a destilação fracionada, em que se evapora a água após separá-la do álcool (UNIÃO DA INDÚSTRIA DE CANA-DE-AÇÚCAR, 2013).

O etanol anidro é misturado à gasolina com os objetivos de tornar o combustível mais barato, aumentar sua octanagem e reduzir a emissão de poluentes. $\mathrm{O}$ Brasil, até 2011, utilizava a mistura na proporção de $20 \%$, passando, depois, para $25 \%$ e atingindo o patamar de $27 \%$ em 2015 (BRASIL, 2017).

Segundo a diretora presidente da União da Indústria de Cana-de-açúcar (Unica), Elizabeth Farina, o aumento do etanol anidro na composição da gasolina é um dos fatores capazes de explicar o aumento da produção de etanol pelas usinas:

O aumento de demanda proporcionado pela volta da mistura de $25 \%$ de etanol anidro na gasolina, a condição superavitária do mercado mundial de açúcar e o potencial de demanda por etanol hidratado em função da enorme frota de veículos flex no país, principalmente nos estados que dão um tratamento diferenciado ao hidratado na aplicação do ICMS (UNICA, 2013, não paginado).

O diretor técnico da Unica, Antônio de Pádua Rodrigues, observa como o aumento da produção do etanol atinge positivamente a economia brasileira: 
Além de atender toda a demanda adicional por combustíveis leves, o restabelecimento da mistura de etanol anidro em $25 \%$ a partir de maio deste ano reduziu a demanda por gasolina pura e permitiu que a Petrobrás elevasse sua capacidade de refino em cerca de $10 \%$, reduzindo de forma significativa a necessidade de importação de gasolina (UNICA, 2013, não paginado).

Já o etanol hidratado é utilizado como combustível no Brasil desde o fim da década de 1970. Como o país tem a maior produção mundial de cana-de-açúcar, melhor matéria-prima do etanol, esse uso torna-se viável economicamente, a partir dos incentivos governamentais com o programa Proálcool, de 1975, como observado no Gráfico 2.

Gráfico 2 - Produção de etanol anidro e hidratado $\left(1.000 \mathrm{~m}^{3}\right)$ entre 1980 e 2014

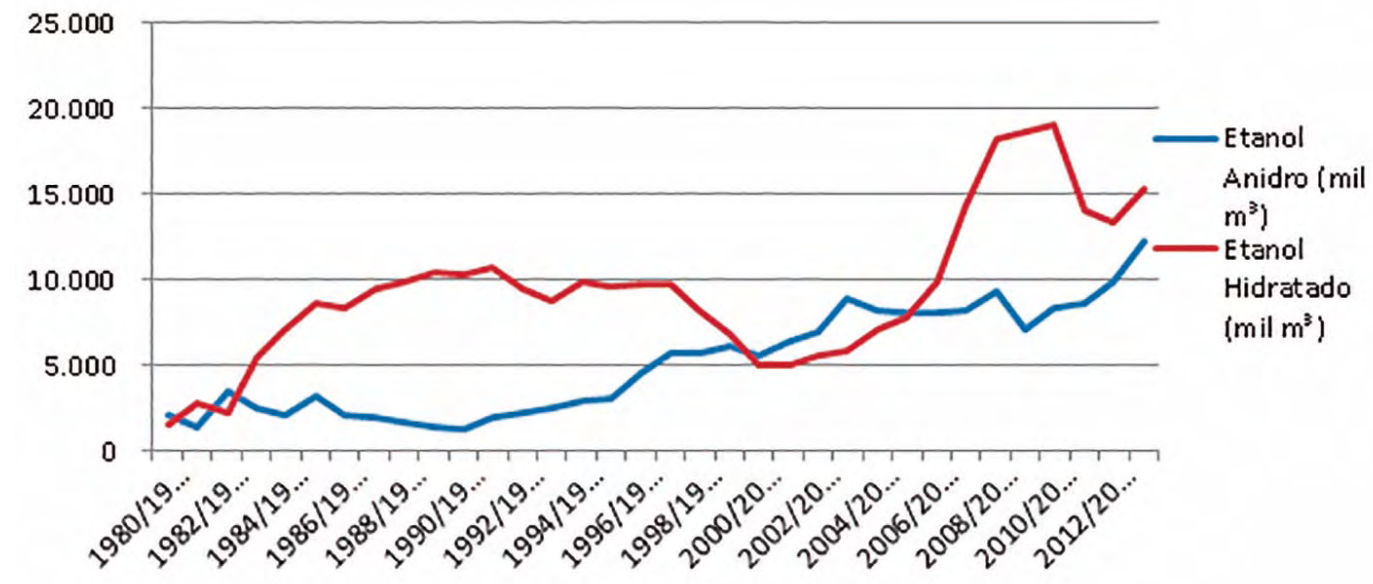

Fonte: elaboração dos autores a partir da Base de dados Unica.

\subsection{Motor flex-fuel: cenário brasileiro}

O Brasil é um dos países em que o biocombustível é o mais usado, e boa parte da tecnologia dos motores e do próprio combustível renovável é feita no país. Os primeiros motores flexíveis (ou flex-fuel) foram desenvolvidos nos anos 1980 pelos Estados Unidos da América, com incentivos fiscais do governo, mesmo com um déficit de infraestrutura de abastecimento. Em 1984, a Ford apresentou os motores com essa nova tecnologia. Em 1992, a General Motors colocou no mercado o primeiro veículo com motor flex no mundo, a van Lumina, que era equipada com um sensor capaz de medir o teor de etanol no combustível (DE SOUZA E MACEDO 2010 p. 163). 
No Brasil, o primeiro protótipo de veículo utilizava o sistema Motronic Flex Fuel, que era capaz de analisar o percentual de etanol e foi desenvolvido pela Bosh, em 1990. Em 2000, a Magneti Marelli desenvolveu um novo sistema, o Software Flexfuel Sensor (SFS), dispensando o uso do sensor capacitivo adicional que era encontrado no protótipo da Bosch. O SFS permitiu a utilização do sensor de oxigênio já utilizado no controle da emissão de poluentes. As montadoras preferiram o SFS ao sistema da Bosh, pois era mais simples, barato e confiável (DE SOUZA, 2010, p. 163).

Essa nova tecnologia recebeu subsídio do governo, beneficiando os veículos flex-fuel com a mesma alíquota de imposto sobre produtos industrializados (IPI) para os veículos a álcool, que era inferior à dos veículos a gasolina. Isso incentivou as montadoras, pois compensou os investimentos realizados no desenvolvimento tecnológico e possibilitou que a tecnologia fosse implantada no país.

Outro aspecto fundamental para a rápida introdução e a evolução da nova tecnologia dos motores, além dos incentivos governamentais, foi a incorporação imediata dos desenvolvimentos anteriores nos motores a etanol, em termos de compatibilidade de materiais, grau térmico da vela de ignição, bomba e filtro de combustível, sistema de partida a frio, dentre outros. Com isso, o país tinha uma vantagem, comparando-se a outros países, por ter uma maior experiência técnica, suficiente para essa fácil adaptação e o aperfeiçoamento de todo o sistema do motor a álcool (DE SOUZA, 2010, p. 163).

Entre o etanol e a gasolina existem várias diferenças essenciais para a escolha do consumidor e o aperfeiçoamento dos veículos a álcool. Uma das grandes dificuldades do uso de etanol em motores de ignição a centelha é a partida e operação a frio. O álcool não consegue alcançar seu potencial a baixas temperaturas ${ }^{3}$.

Outra característica importante que diferencia o etanol da gasolina, e que merece ser mais explorada nos veículos flexíveis, é sua maior resistência à autocombustão. Essa maior “octanagem” possibilita aumentar a taxa de compressão do motor e obter maior rendimento térmico.

A utilização de motores de baixa cilindrada sobre alimentados ${ }^{4}$ em aplicações típicas de motores maiores pode ser uma excelente oportunidade de valorizar a alta octanagem e o calor latente de vaporização do etanol. Tendo em vista que os motores de baixa cilindrada são de carros populares, logo, o etanol, sendo já um combustível mais barato do que a gasolina, tem como vantagem a mais sob o combustível fóssil o melhor funcionamento nos carros "populares", que são os de menor valor, fortalecendo a aceitação da população pelos veículos movidos a álcool (DE SOUZA, 2010, p. 163). 
Com a chegada dos veículos flex-fuel, aumentou o poder de decisão do consumidor sobre qual combustível abastecer, de modo que o etanol e a gasolina se transformaram em bens substitutos. Assim cada agente econômico toma a decisão de demandar um bem ou outro, guiando-se pela otimização da utilidade de cada bem.

Com o aumento de vendas dos carros flexíveis, o etanol, que era menos consumido, teve um crescimento na sua demanda, acompanhado por um aumento da oferta por parte das usinas sucroalcooleiras. Como o combustível renovável é um produto agrícola, logo, a oferta não consegue acompanhar com a mesma velocidade a demanda, portanto, ocorre uma elevação do preço.

No Gráfico 3, apresentam-se os preços da gasolina e do etanol, com o recorte histórico: pré carro flexível (2002), um ano após a entrada no mercado (2004) e após dez anos (2014), o que ajuda a observar o impacto causado pela entrada dessa nova tecnologia no mercado de combustíveis.

Gráfico 3 - Preços da gasolina e do etanol nos anos 2002, 2004 e 2014

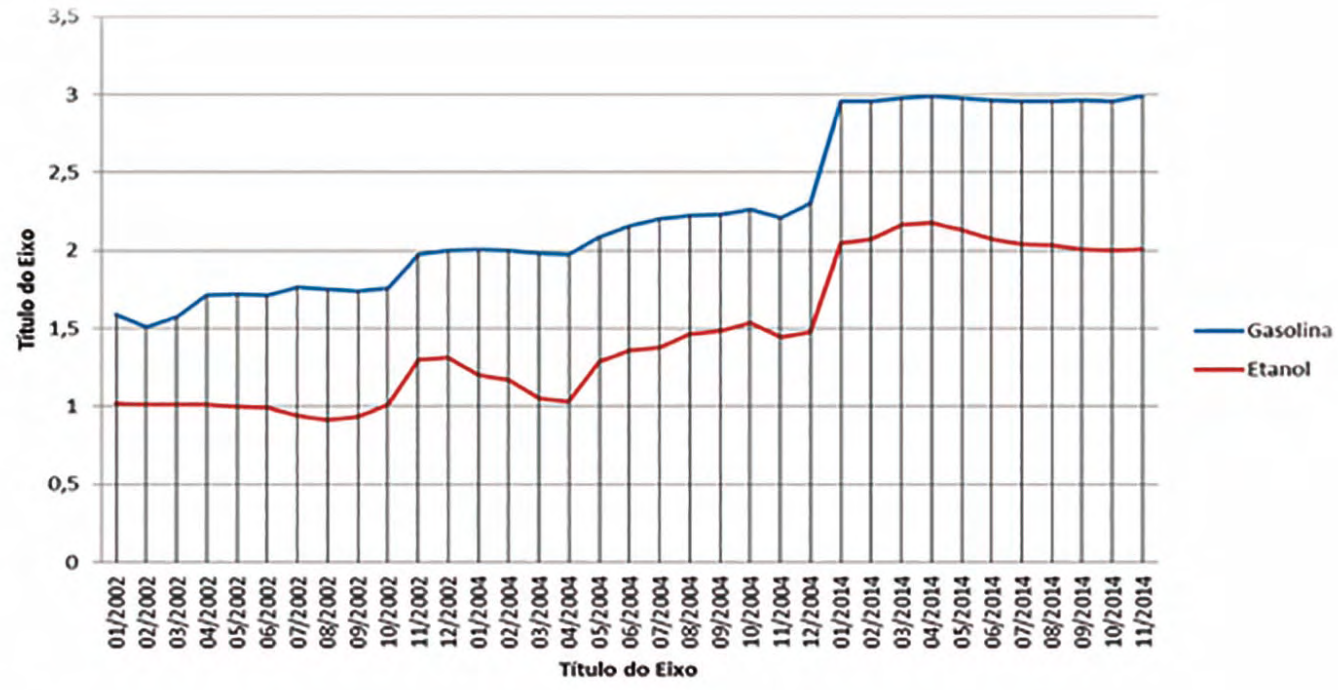

Fonte: elaboração dos autores a partir da Base de dados ANP.

No Gráfico 3, é possível observar que, praticamente em todo o ano de 2002, o preço do etanol se manteve estável, já a gasolina teve pequenas variações, mostrando a não existência de correlação entre o preço dos dois combustíveis. Com a chegada do carro flex-fuel em 2003, verifica-se o impacto nos primeiros meses de 2004, quando o etanol estava com preço elevado, devido à crescente demanda pelo combustível; logo após, começou um movimento de queda no preço, com a colheita e 
o refino da cana-de-açúcar e a opção do produtor pelo etanol, aumentando a oferta do produto. Na segunda metade do ano, contudo, os preços se elevaram novamente, podendo ser relacionado à entressafra e ao grande sucesso do novo motor.

Em 2014, os preços tanto do etanol quanto da gasolina se mantiveram estáveis. Esse movimento foi causado muito por conta da política intervencionista do governo de controle dos preços dos combustíveis para tentar segurar uma inflação crescente, que já estava acima do teto da meta.

O Gráfico 4 apresenta um recorte histórico da venda de carros a partir do ano de 1979 até janeiro de 2014, identificando-se o tipo de combustível utilizado pelos motores: gasolina, etanol ou ambos. É possível observar as tendências das montadoras e dos consumidores com o aparecimento de novas tecnologias.

Gráfico 4 - Vendas anuais de automóveis e veículos comerciais leves novos no Brasil

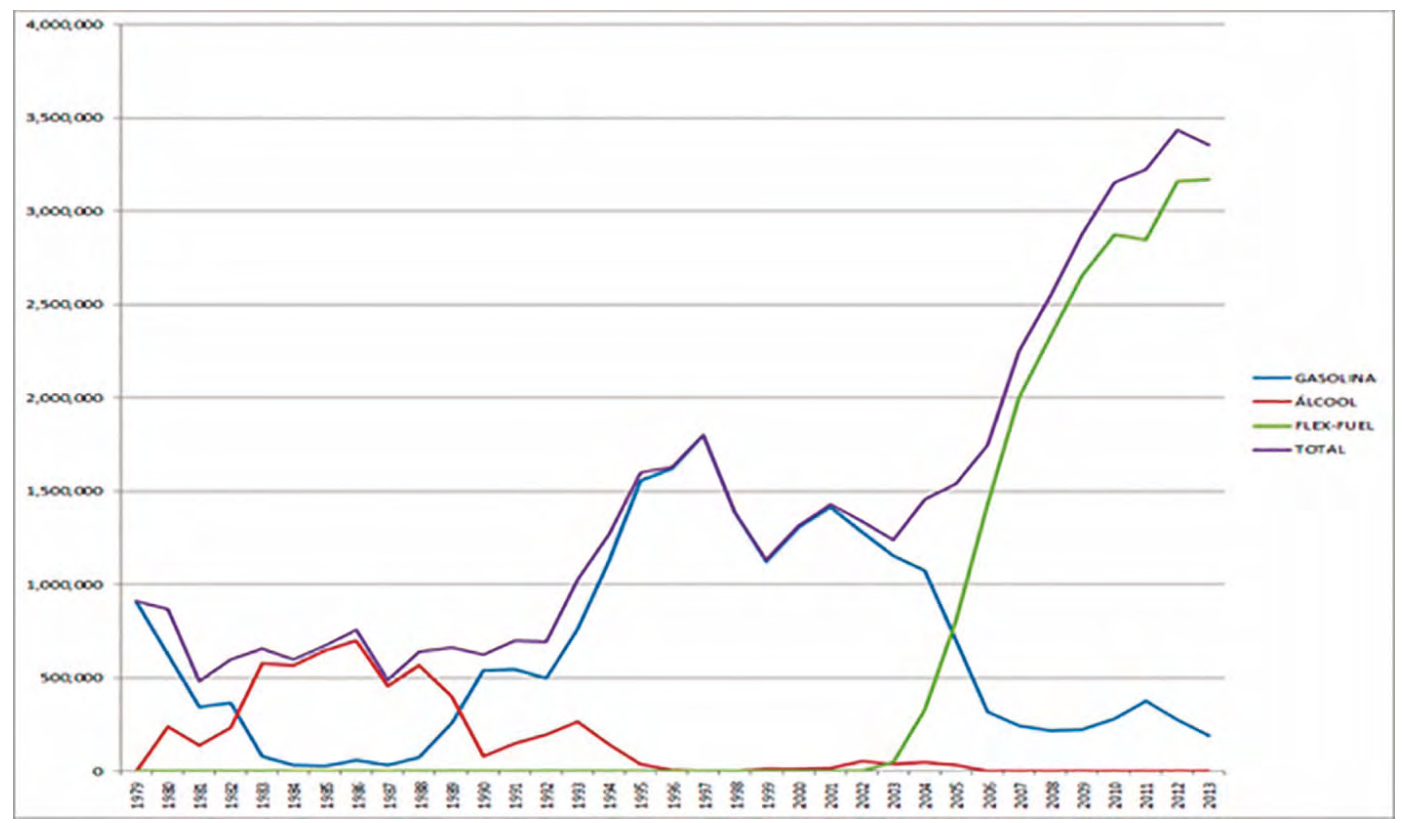

Fonte: elaboração dos autores a partir da Base de dados Unica.

Como visto no Gráfico 4, com o aparecimento e a popularização do carro movido a álcool, as vendas dos veículos movidos a gasolina obtiveram uma forte queda no final de 1970 e por toda a década de 1980. No início de 1990, após a criação do plano econômico do Real e o controle da inflação, houve uma inversão no panorama do mercado automobilístico, isto é, os veículos a etanol praticamente sumiram do mercado, e o motor a combustível fóssil passou a ocupar o mercado. O começo do 
desaparecimento total do carro movido somente a álcool ocorre com o desenvolvimento do motor flex-fuel, que logo ganha mercado, por ter a vantagem de o agente econômico conseguir otimizar sua utilidade; rapidamente as vendas se equipararam e, logo, ultrapassaram as vendas de veículos a gasolina, que começaram a ter seu espaço reduzido no mercado.

\section{Mercado: trade-off entre açúcar e etanol}

O açúcar e o etanol são produtos gerados do cultivo da cana-de-açúcar, ambos são produzidos na mesma refinaria, logo, não se faz necessário ter uma para cada produto. Esse fato faz com que o produtor escolha entre um produto ou outro, com base na maior satisfação e na maximização dos lucros. Portanto, o açúcar e o etanol são bens não complementares para o processo produtivo.

A partir dessa noção de bens não complementares, a oferta entre os dois produtos se dá pela simples questão de preço de mercado, um trade-off ${ }^{5}$ enfrentado pelas usinas. $\mathrm{O}$ etanol tem maior parte da sua oferta voltada ao mercado interno e o açúcar tem parte de sua produção exportada e outra consumida internamente. $O$ valor do açúcar no mercado internacional afeta diretamente a quantidade ofertada de etanol para o mercado nacional, agindo no preço do biocombustível. Então, a decisão da produção nas usinas é moldada perante a análise de preço do açúcar, internacionalmente, e do etanol, nacionalmente.

Na Tabela 2, pode-se observar o crescimento na moagem total da cana-de-açúcar desde 1980 até 2014, o que demonstra uma clara evolução produtiva no insumo, na safra 1980/1981, com 123.681 toneladas, pulando para 653.519 toneladas na safra $2013 / 2014$, um crescimento de $528 \%$ da produção total de cana-de-açúcar. Já a parte destinada para o etanol na safra 1980/1981 com $3.706 \mathrm{~m}^{3}$, passa para $27.543 \mathrm{~m}^{3}$ na safra $2013 / 2014$, um crescimento de $743 \%$ da produção de cana-de-açúcar destinada ao etanol. A quantidade total de cana-de-açúcar destinada ao açúcar na safra 1980/1981, com 8.254 toneladas, passa para 37.713 toneladas na safra $2013 / 2014$, um crescimento de $457 \%$ da produção.

Com isso, pode-se observar que, apesar das intempéries enfrentadas pelo etanol ao longo dos anos, seu espaço no mercado aumentou em relação ao açúcar. Enquanto a parte destinada ao açúcar na produção da cana-de-açúcar cresceu $457 \%$, a parte destinada ao etanol cresceu $743 \%$. Essa comparação em valores efetivos do crescimento entre os produtos finais da safra de cana-de-açúcar pode ser melhor observada no Gráfico 5, no qual verifica-se que o etanol só ultrapassou o açúcar na década de 1980, mantendo-se abaixo ao longo de toda a década de 1990 até 2014 . 
Tabela 2 - Moagem total de cana-de-açúcar e partes destinadas à produção de etanol e de açúcar nas safras de 1980 a 2014

\begin{tabular}{l|c|c|c|c|c|c}
\cline { 2 - 7 } & $1980 / 1981$ & $1990 / 1991$ & $2000 / 2001$ & $2003 / 2004$ & $2005 / 2006$ & $2013 / 2014$ \\
\hline $\begin{array}{l}\text { Moagem total (mil } \\
\text { toneladas) }\end{array}$ & 123.681 & 222.429 & 256.818 & 358.762 & 385.129 & 653.519 \\
\hline Etanol (mil m²) & 3.706 & 11.515 & 10.592 & 14.736 & 15.821 & 27.543 \\
\hline Açúcar (mil toneladas) & 8.254 & 7.365 & 16.198 & 24.919 & 25.823 & 37.713 \\
\hline
\end{tabular}

Fonte: elaboração dos autores a partir da Base de dados Unica.

Gráfico 5 - Moagem de cana-de-açúcar e o produto final nas safras de 1980 a 2014

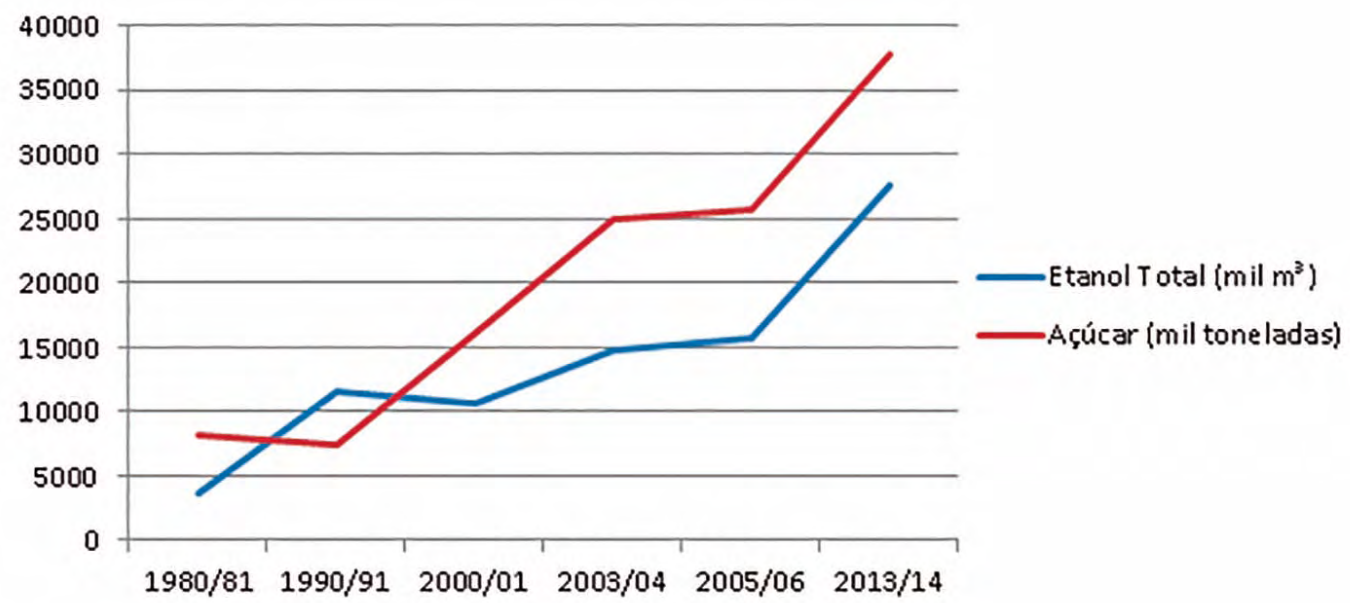

Fonte: elaboração dos autores a partir da Base de dados Unica.

As variações na produção de etanol, açúcar e cana-de-açúcar podem ser observadas no Gráfico 6. Percebe-se um padrão na produção ao longo do período observado. Os incentivos do Proálcool, no final da década de 1970, surtiram efeito no início da década de 1980, com a elevação acentuada da taxa de variação percentil da safra de cana-de-açúcar. O interessante é que, ao longo dos anos, observa-se certa sintonia entre os fatores, principalmente a convergência entre as variáveis no que diz respeito a tendências de declínio e ascensão. No período de altos investimentos, nos anos 1980, percebe-se um boom na produção de cana-de-açúcar, o que pode ser explicado pelos grandes incentivos recebidos. 
Gráfico 6 - Taxa de variação percentil da produção por safra (1981 a 2015)

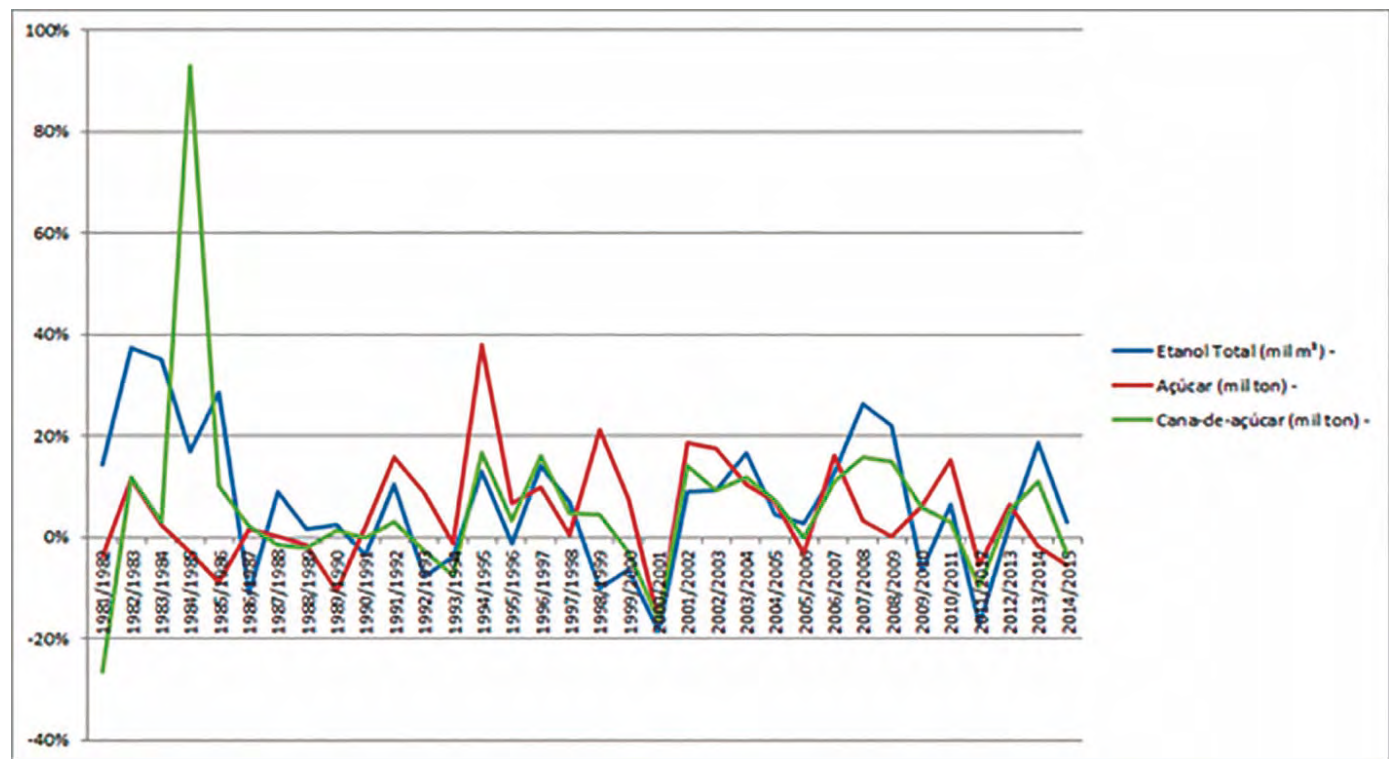

Fonte: elaboração dos autores a partir da Base de dados Unica.

\subsection{Proálcool: leitura de mercado}

Com o Proálcool e a chegada dos carros movidos a etanol, nos postos de abastecimento, o combustível renovável dividiu espaço com a gasolina já no final de 1970, ganhando espaço a partir de 1980. Apesar de toda a crise vivida no país durante a década de 1980, o carro movido a álcool ganhou espaço e continuou crescendo até a abertura comercial e a estabilização econômica a partir do plano Real, em 1994. Ao abrir o país comercialmente, os automóveis importados invadiram o mercado, sem dar chance ao automóvel nacional movido a etanol, de tal forma que a demanda por carro a álcool quase desapareceu. 
Gráfico 7 - Vendas de veículos movidos a etanol entre 1990 e 2002

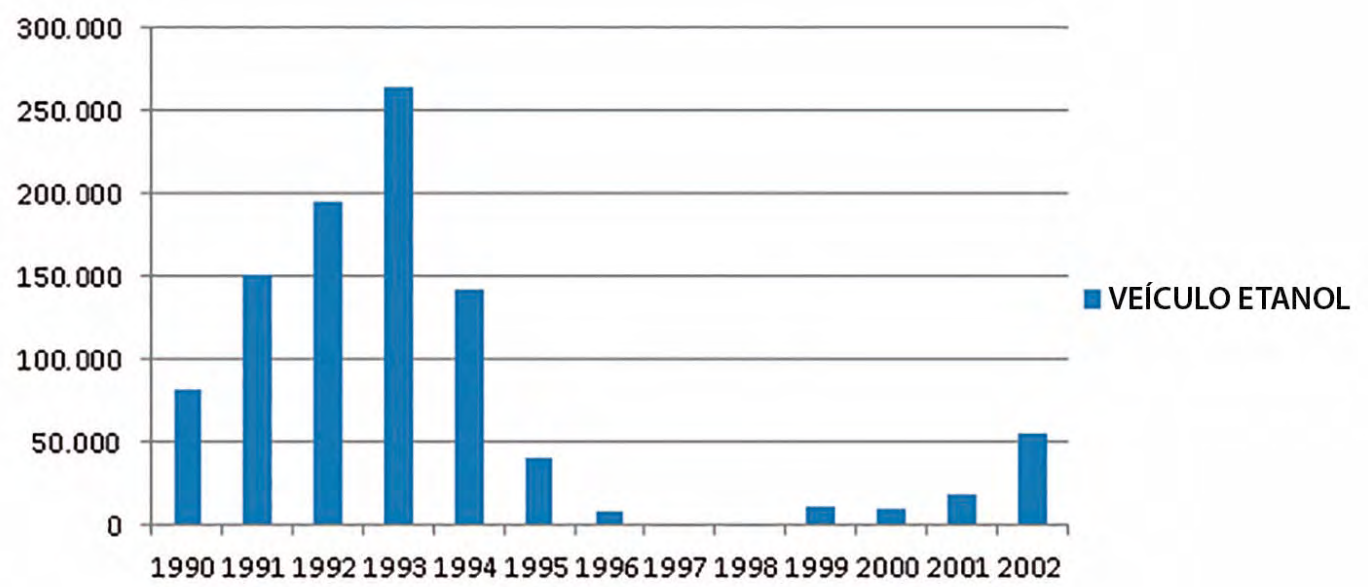

Fonte: elaboração dos autores a partir da Base de dados Unica.

Nesse contexto, em março de 2003, iniciava-se uma evolução na indústria automobilística, com o lançamento do primeiro veículo flexível brasileiro, capaz de consumir etanol hidratado, gasolina ou qualquer mistura entre os dois combustíveis, de modo a dar ao usuário final o direito de escolha do combustível a cada abastecimento. Diferente de hoje, nas décadas de 1980 e 1990, os carros não eram flex, consequentemente, os combustíveis não eram substitutos perfeitos do ponto de vista econômico.

A partir do motor flex-fuel, os combustíveis renováveis e fósseis transformam-se em bens substitutos, se o preço do álcool for até 70\% do preço da gasolina. Essa tecnologia deu uma informação mais perfeita para o agente econômico, que passa a ser capaz de considerar os custos de cada combustível e, assim, escolher o melhor preço por quilômetro rodado. Essa perfeita mobilidade dos fatores, a livre escolha entre etanol e gasolina, fez com que os veículos que funcionavam somente com o etanol fossem sumindo do mercado, ao passo que os carros com motor flexível cresceram exponencialmente, como pode ser observado no Gráfico 5.

Ao passar por várias crises, nos preços tanto do petróleo quanto do açúcar, o cultivo da cana-de-açúcar no Brasil teve um movimento ascendente, o que proporcionou um excedente de matéria essencial para o destaque brasileiro no biocombustível, pois, a partir desse excedente e da insistência do governo, o país foi capaz de aperfeiçoar tecnologicamente o combustível, o motor flex-fuel e os componentes dos veículos. 
Gráfico 8 - Moagem de cana-de-açúcar (mil toneladas) entre as safras de 1980 a 2014

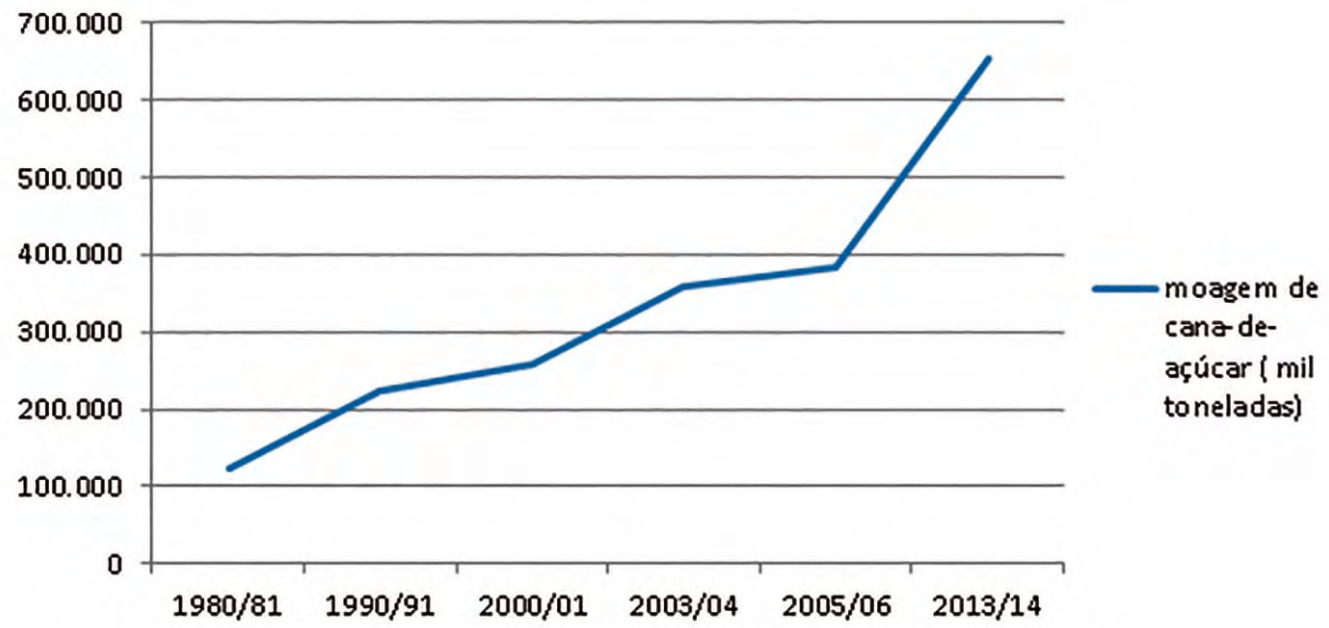

Fonte: elaboração dos autores a partir da Base de dados Unica.

O Gráfico 8 evidencia o crescimento da moagem de cana-de-açúcar, demonstrando o aumento da expectativa do produtor em investir na ampliação da safra, após o Proálcool. Nesse sentido, as políticas adotadas pelo governo foram eficazes para a produção agrícola destinada à cana-de-açúcar.

A partir do Proálcool, as usinas e as destilarias foram capazes de enfrentar as crises existentes no Brasil no final do século XX. Prova disso é que a moagem da cana-de-açúcar no país não parou de crescer, com a ajuda do Proálcool em 1975, a liberalização das exportações de açúcar em 1990, a desregulamentação do setor sucroalcooleiro em 2000, o início da produção dos carros flex-fuel, a construção de instalações de novas usinas, o aumento das exportações do álcool e, em 2014, a consolidação desse combustível na sociedade.

\section{Considerações finais}

A biomassa é uma matriz energética limpa e renovável. Em tempos da incessante busca por novas fontes de energia, para responder aos anseios da sociedade na substituição dos combustíveis fosseis, o Brasil sai na frente, com a utilização da cana-de-açúcar na geração de energia.

O começo dessa história no país foi há 40 anos com o Proálcool. Perante a crise do petróleo, como solução aos problemas, o álcool foi a forma que o país encontrou 
para tentar substituir a gasolina. Durante os anos 1980 e 1990, o etanol passou por crises no preço do petróleo e do açúcar, quase levando ao fracasso do projeto. Contudo, a ascensão veio no começo do novo milênio com o lançamento dos veículos com motor flex-fuel, que pode utilizar a gasolina e o etanol. O etanol revelou-se uma excelente saída para um combustível renovável e com menos liberação de gases causadores do efeito estufa, se comparado à gasolina.

A motivação inicial do projeto do governo para o incentivo aos investimentos ao etanol, o Proálcool, foi o preço do petróleo, que se elevou fortemente e fez com que os custos marginais de produção de tecnologias para combustíveis renováveis fossem viáveis. Outro problema causado pelo aumento do barril de petróleo foi a deterioração dos termos de troca com a importação do combustível. Logo, o etanol como via de substituição de importação foi uma forma de amenizar o déficit na balança de pagamentos.

O etanol foi aprimorado ao longo do tempo e, com os estímulos do governo, passou por uma evolução tecnológica, visando garantir a diversificação da matriz energética e, atualmente, diminuir a emissão dos gases do efeito estufa. Assim, o Brasil desenvolveu um setor importante da economia, o automobilístico, a partir de novo paradigma sustentável com o combustível verde, o etanol. 


\title{
Ethanol: 40 years of evolution of the fuel and automobile market in Brazil
}

\begin{abstract}
This article aims to historically analyze with the relevant data and how behaved the market of fuels and automobiles since the government project, Proálcool, until 2014. If used data from the grinding of sugarcane for separate final destination, sugar or ethanol. Also, observed the automobile market separated by fuel type accepted by each engine.
\end{abstract}

Keywords: Ethanol. Automotive market. Fuel market. Proálcool.

\section{Etanol: 40 años de evolución de combustible y el mercado de automóviles em Brasil \\ Resumen}

Este artículo se pretende analizar historicamente com los datos relevantes ya que el mercado se comporto de combustible y los automóviles com el inicio del proyecto del gobierno, llamado Proalcohol hasta el año 2014. Utilizado los datos a partir de la molienda de la caña de azúcar por su separada em su destino final, azúcar y etanol. Además, se observo el mercado del automóvile separados por tipo de combustible aceptada por cada motor.

Palabras claves: Etanol. Mercado de la autmoción. Mercado de combustible. Proalcahol.

JEL: Q41, Q16, Q48, 


\section{Notas}

1 Disponívelem:<http://www.worldbank.org/projects/P006313/alcohol-biomas-energy-development-project? lang=pt>. Acesso em: Acesso em: 28 mai. 2018.

2 Disponível em: <http://www.novacana.com/etanol/anidro-hidratado-diferencas/>. Acesso em: 25 out. 2014.

3 Para resolver esse problema, os carros flex-fuel fabricados a partir de 2003 têm "tanquinho" de partida de motor a frio. Nele, vai cerca de um litro de gasolina, que é injetada no motor somente para a primeira partida do veículo quando a temperatura ambiente está abaixo da faixa dos $15 \square$ C e o carro está com etanol no tanque. Isso serve para facilitar o arranque e evitar falhas nos primeiros minutos, já que o etanol tem menor poder de explosão quando o motor está frio.

4 O termo trade-off é utilizado na economia e diz respeito ao processo em que há um conflito de escolha e suas implicações (PINDYCK E RUBINFELD, 2010).

5 o termo "sobre alimentados" significa introduzir maior quantidade de ar ou de mistura de explosão, dependendo do tipo de alimentação do motor (diesel ou mistura), para aumentar a potência do motor. Então, o etanol ganha em poder calorífico em relação ao combustível fóssil, sendo assim mais indicado para os veículos populares.”

\section{Referências}

BACCARIN, José Giacomo. A desregulamentação e o desempenho do complexo sucroalcooleiro no Brasil. São Carlos: UFSCar, 2005. Disponível em: <http://www.ipea.gov.br/desafios/index. php?option=com_content\&view=article\&id=2321:catid=28\&Itemid=23>. Acesso em: 25 out. 2014.

BELLUZZO, Luiz Gonzaga de Mello. O declínio de Bretton Woods e a emergência dos mercados "globalizados". Economia e Sociedade, Campinas, v. 4, n. 1, p. 11-20, 1995.

BRASIL. Portal Brasil. Governo estabelece adição de 27\% de etanol na gasolina. 05 mar 2015. Disponível em: <http://www.brasil.gov.br/economia-e-emprego/2015/03/adicao-de-27-de-etanol-na-gasolina-e-estabelecida-pelo-governo>. Acesso em: 13 abr. 2017.

CARNEIRO, R. Desenvolvimento em crise: a economia brasileira no último quarto do século XX. São Paulo: Editora Unesp; IE - Unicamp, 2002. (Coleção Economia Contemporânea).

CAVALCANTI, Guilherme de Albuquerque. A dinâmica econômica do Proálcool: acumulação e crise 1975-1989. Revista Brasileira de Energia, Itajubá, v. 2, n. 1, 1992.

DE SOUZA, Eduardo L. Leão; MACEDO, Isaias de Carvalho. Etanol e bioeletricidade: cana-de-açúcar no futuro da matriz energética. Unica. São Paulo: Editora Luc, 2010.

FRAQUELLI, A. C. O ambiente econômico internacional e o comportamento dos preços do barril de petróleo. 2014. Disponível em: <revistas.fee.tche.br/index.php/indicadores/article/download/1651/2021>. Acesso em: 20 nov. 2015.

FURTADO, C. Formação econômica do Brasil. São Paulo: Companhia Editora Nacional, 1975.

MARJOTTA-MAISTRO, M. C. Ajustes nos mercados de álcool e gasolina no processo de desregulamentação. Piracicaba: Esalq, 2002.

MATHIAS, João Felippe Cury Marinho. Modernização e produtividade da agropecuária no Brasil. 2014. Disponível em: <http://comovaiobrasil.pressbooks.com/chapter/modernizacao-e-produtividade-do-agronegocio-no-brasil/>. Acesso em: 26 nov. 2015. 
NITSCH, Manfred. O programa de biocombustível Proálcool no contexto da estratégia energética brasileira. Revista de Economia Política, v. 2, 1991.

PIMENTEL, Fernando. O fim da era do petróleo e a mudança do paradigma energético mundial: perspectivas e desafios para a atuação diplomática brasileira. Rio de Janeiro: Ministério das relações Exteriores; Fundação Alexandre de Gusmão, 2011.

PIMENTEL, Diego Alves. Indicadores de vulnerabilidade de produtores de petróleo: o caso Opep. Rio de Janeiro: COPPE/UFRJ, 2006.

PINDYCK, Robert S; RUBINFELD, Daniel L. Microeconomia. 7. ed. São Paulo: Pearson Education do Brasil, 2010.

UNIÃO DA INDÚSTRIA DE CANA-DE-AÇÚCAR. Safra 2013 / 2014 tem oferta recorde de etanol no centro-sul, desempenho com pouca possibilidade de se repetir no futuro. 2013. Disponível em: <http://www.unica.com.br/imprensa/17830428920328781316/safra-2013-por-cento2F2014-tem-oferta-recorde-de-etanol-no-centro-sul-por-cento2C-desempenho-com-pouca-possibilidade-de-se-repetir-no-futuro/>. Acesso em: 25 out. 2014.

SANTOS, Maria Helena de Castro. Álcool: subproduto do açúcar ou combustível? Uma perspectiva histórica, 1900:75. Rio de Janeiro: Finep, 1982. 